\title{
Expanding Support for Graduate Students: Library Workshops on Research Funding Opportunities
}

\author{
Carrie Forbes, Gina Schlesselman-Tarango, and \\ Peggy Keeran*
}

\begin{abstract}
This case study describes the development, implementation, and assessment of a series of grants research workshops for graduate students, which were implemented to fill a gap in graduate student support. We assessed the workshops through a series of focus groups, and findings show overall satisfaction with the grants tools and workshop. However, participants noted areas of improvement around outreach and promotion and general communication with graduate students. Additional themes emerged related to graduate student socialization and research behaviors, which suggests that librarians have an important role to serve in these areas.
\end{abstract}

The current environment of research in higher education is characterized by emerging technologies and an exponential rise in information, a focus on interdisciplinary research, expanding faculty workloads, and greater calls for accountability. ${ }^{1}$ Regardless of the institutional type, the modern college or university is also increasingly reliant on funding from external constituencies to support faculty research. ${ }^{2}$ Within this new research paradigm, the implications for graduate students, as future faculty members and professionals, are extensive. In addition to the traditional expectations for teaching, research, and service, they need to understand the broader expectations for scholarship and develop expertise in the different forms of scholarly work. They must be able to collaborate with colleagues in other disciplines and with individuals and organizations outside the academic environment while at the same time raising funds for their own research. ${ }^{3}$

The University of Denver (DU) is a private, coeducational research university with a graduate student population of approximately $6,261,{ }^{4}$ with a total of 11,780 students. ${ }^{5}$ The Office of Graduate Studies oversees admissions, theses and dissertation processing, career services, and budgets, with a focus on student academic success. The Graduate Student Governance fosters a sense of community and advocates for graduate students,

* Carrie Forbes is Associate Dean for Student and Scholar Services at the University of Denver; e-mail: Carrie.Forbes@du.edu. Gina Schlesselman-Tarango is Instructional Services and Initiatives Librarian at California State University, San Bernardino; e-mail: gschlesselman@csusb.edu. Peggy Keeran is Arts E Humanities Reference Librarian at the University of Denver; e-mail: Peggy.Keeran@du.edu. (C2017 Carrie Forbes, Gina Schlesselman-Tarango, and Peggy Keeran, Attribution-NonCommercial (http://creativecommons.org/licenses/by-nc/4.0/) CC BY-NC. 
arranging meetings to discuss issues, workshops on topics of interest, and an annual summit for presenting research to the academic community. Yet, DU has a decentralized structure, which means that individual schools and colleges offer services and support for their own students that are not necessarily available to all graduate students. Because of the institution's decentralized organization, some graduate students are missing research and professional skills that would help them prosper in academia and in their future careers. The librarians, recognizing this inconsistency as a challenge for a large part of our community, identified gaps in the graduate student experience at DU and created instructional programming to provide graduate students with opportunities to develop foundational research skills.

In this paper, we describe the development, implementation, and assessment of a series of grants research workshops, a relatively new venture for us because, in the past, we had not considered that librarians had a role in teaching students to search for funding opportunities. We chose the workshop for this case study to determine whether graduate students recognized it as valuable, effective, and meeting a need, and because this specific topic is not addressed in the library literature. We assessed the workshops through a series of focus-group interviews with workshop participants. Findings show overall satisfaction with the grants tools and workshop, but participants noted areas of improvement around outreach and promotion and general communication with graduate students. Additional themes also emerged related to graduate student socialization and research behaviors. We discovered that, not only does the grants research workshop meet a real need, but our graduate students perceive librarians as having a broader, collaborative role both in their academic and professional success and socialization. Based upon our research and the student feedback, we believe this study will show that librarians can find and fill gaps in the graduate student experience and effectively teach them skills that will help them thrive in the new research paradigm of the twenty-first century.

\section{Literature Review}

Many postbaccalaureate degree programs, academic departments, and graduate and professional schools offer various services and resources for students. However, divisions of student affairs, especially those at research universities, typically focus on undergraduate students, hence devoting less effort to engaging the graduate and professional student population. The assumption is that graduate students, having experienced higher education as undergraduates, understand how to navigate institutional bureaucracies, thus warranting less attention than current undergraduates. ${ }^{6}$ Another issue is that graduate students have specific needs and face developmental challenges that may differ from, but are as important as, those experienced by undergraduates. While many academic departments provide some support for graduate students, they often suffer from a building-bound silo effect that isolates them from the larger university. Academic units, and even offices for graduate support services, usually lack the human resources to adequately address many issues such as research funding and career development.?

As graduate students transition from being consumers to creators of knowledge, they are often in need of additional support structures beyond their departmental advisor and peers. ${ }^{8}$ According to Ann E. Austin, graduate students typically do not receive systematic opportunities to develop needed skills and abilities in research and teaching. ${ }^{9}$ In recent years, there has been a growing interest in the role that information literacy instruction plays in the success of graduate students. In a literature review on graduate students and library instruction, Barbara Blummer notes that there have been a large variety of instructional efforts aimed at graduate students including faculty-librarian partnerships, seminars and workshops, and for-credit courses. ${ }^{10}$ 
Library instruction for graduate students has been shown to increase both skill level and confidence, regardless of the mode of delivery. ${ }^{11}$ Workshops specifically targeting the unique needs of graduate students increase proficiency and help students feel more effective and efficient in their information seeking. ${ }^{12}$ Involving a librarian can also help to reduce graduate student attrition and improve degree completion rates. ${ }^{13}$ Librarians can assist graduate students in determining how to begin and proceed through the literature research process, alleviating the associated anxiety many students experience along the way. ${ }^{14}$ In doing this, librarians establish meaningful relationships with those they serve and become a trusted partner, consequently fulfilling students' affective needs, such as those tied to successful socialization into a discipline, that are commonly overlooked within the traditional structure of the academy. According to Michelle Holschuh Simmons, academic librarians occupy a unique position within the academy as professionals who are familiar with disciplinary conventions and research but who are not a part of the formal structure of evaluation of students' research. It is this position that provides librarians with the opportunity to "mediate" between the academic discourse and norms of the academy and the student experience. ${ }^{15}$

As librarians begin to expand their support services for faculty to include data management and scholarly communications, a small but growing body of literature is now discussing how to teach graduate students these same skills. ${ }^{16}$ Most of this research assumes, however, that graduate students are participating in faculty-led grant projects, so little attention has been paid to supporting graduate students searching for funding. ${ }^{17}$ While doctoral students in science are often supported by external and internal research monies, in the humanities they are most frequently supported by teaching assistantships, which slows their time to completion and increases their need for funding in the final years of their programs. With an increase in nontraditional students, parents, and students attending part-time, the length of time it takes to earn a doctorate has also risen dramatically in the last several years. Graduate students, especially doctoral students, often run out of assistantships and other university funding opportunities prior to the completion of their degree. ${ }^{18}$

Graduate students today, particularly doctoral students in the humanities and social sciences, have an urgent need to secure funding for research, conference travel, and scholarships to complete their programs. At the same time, they must also learn how to raise their own research funds if they are to be successful faculty members going forward. As universities are just beginning to reevaluate their support structures for graduate students, ${ }^{19}$ academic librarians can help fill this important gap through workshops, programming, and collaborative support services.

\section{Background}

The library faculty at DU serve a graduate population, enrolled in both academic and professional programs, that slightly outnumbers the undergraduates. As of 2014, approximately 71 percent of graduate students were in masters-level programs, while the remaining 29 percent were in doctoral programs (see figure 1). ${ }^{20}$

The library has a strong communication link, via in-person meetings and a distribution list, with the academic community through the library liaison advisory group, which includes a faculty representative from every department except law.

Library research workshops that expanded on the material covered in course-related instruction were first offered in 2006-2007 and addressed topics such as RefWorks and Google Scholar, which proved popular with graduate students. Reference librarians continued to develop specialized services for graduate students, who often do not have a centralized support system on campus to help them be successful. As a result, we broadened our offerings over the following years, looking specifically for gaps, and we 
developed workshops on grants funding research, advanced RefWorks, and literature reviews. Most recently we have added a workshop on data management and are planning to develop one on Digital Humanities. Both in-person and online workshops are offered.

In a decentralized institution such as ours, it is often difficult to find a single place for graduate students to get help finding external grants. The Office of Sponsored Research works with faculty, not students, to find funding opportunities, and, although the Office of Graduate Studies offers an internal grant for graduate students presenting at conferences, it is not a resource for finding external grants. As graduate students were asking questions about grants at the research center and in library instruction classes, and because we could not find a department that offered this service for the graduate population as a whole, we identified it as a gap and decided to develop a workshop to determine if there was interest. We began offering the grants research workshops in 2009, with 29 graduate students attending the two workshops. During the next two years, interest fluctuated (largely because the library was being renovated and it was difficult to draw students to workshops located elsewhere), but it has attracted students again since our return to the library. We promoted the workshop by posting announcements throughout the library as well as through the campus's central communication portal, the library liaison e-mail list, library website, Facebook, and Twitter. Sixty graduate students participated in 2012-2013, and forty seven in 2013-2014; the grants workshops trend a little higher than normal for all library workshops. During these years, attendees came from various disciplines (such as international studies, accountancy, chemistry, biology, geography, literature, art, psychology, music). The workshop covered tips and best practices for research grant opportunities, and basic and advanced search strategies in grants databases and association websites.

Although we observed that we were fulfilling a need for graduate students in terms of knowing how to find funding, we decided to assess this specific workshop to determine if we were meeting students' expectations. Questions we had about its effectiveness included:

- Do graduate students find the workshop helpful? If so, in which ways is it helpful?

- What elements of the workshop are the most useful for students?

- How can the workshop be improved?

- Has anyone successfully applied for a grant as a result of the workshop?

- What other areas of support do graduate students need to be successful?

\section{Methodology}

The aim of this study was to hear from graduate students who had attended one or more of the library's grants workshops. In addition to seeking feedback about the workshop, we were interested in graduate students' needs surrounding funding and research support at the campus level. We were specifically interested in developing a clearer understanding of how the library might play a role in better supporting graduate students, be it through workshops or otherwise, and we intended to distribute our findings to other campus entities that might also be interested in graduate student research and funding needs.

For this case study, we chose to use focus group interviewing due to its usefulness in generating impressions of products or programs, diagnosing potential problems, and obtaining new insights and knowledge about phenomena of interest. ${ }^{21}$ Robert Merton explained that the basic purpose of the "focussed" interview (his preferred spelling) was to gather qualitative data from individuals who have experienced some "particular concrete situation," which serves as the focus of the interview. ${ }^{22}$ The objec- 
tive of studying and learning about a "particular concrete situation" implies that an interview, whether individual or group, will be relatively singular in focus. This element contrasts with the typical uses of survey research to gather statistical measures of numerous topics and variables, and this is why focus groups are commonly prescribed for research that is exploratory, clinical, and/or phenomenological. ${ }^{23}$

A second signature aspect of a focus group is the objective to better understand the group dynamics that affect individuals' perceptions, information processing, and decision making. Also, stimulating interactions among group participants are hypothesized to generate more information than individual interviews would provide. ${ }^{24}$ As one of the goals of our focus groups was to solicit feedback on graduate students' experiences with finding funding, we determined that a group interview would allow students to learn from each other as well as detail important information on their experiences.

In an effort to systematically solicit feedback about the workshop, including its content, design, and promotion, we conducted five focus groups over the course of the 2013-2014 academic year. We held focus groups with students who were recruited at the workshop they had attended that same quarter, allowing for immediate engagement with and accurate sampling of participants from quarter to quarter. ${ }^{25}$ We welcomed masters and doctoral students who were at any point in their graduate-level experience, and participants ranged from those in their first to sixth years. Free pizza and a \$25 Amazon gift card served as incentives for participation. The University of Denver's Institutional Review Board (IRB) granted approval for the study, and all participants signed approved consent forms.

The focus groups had five, four, seven, six, and four participants respectively. While we had relatively low numbers of participants in each of the focus groups, the 26 total participants represented 55 percent of all 2013-2014 workshop attendees. Fourteen of the focus group participants (54 percent) were masters-level, and twelve (46 percent) were enrolled in doctoral programs. It should be noted that we had heavy doctoral student representation when compared to DU graduate student makeup (see figure 1).

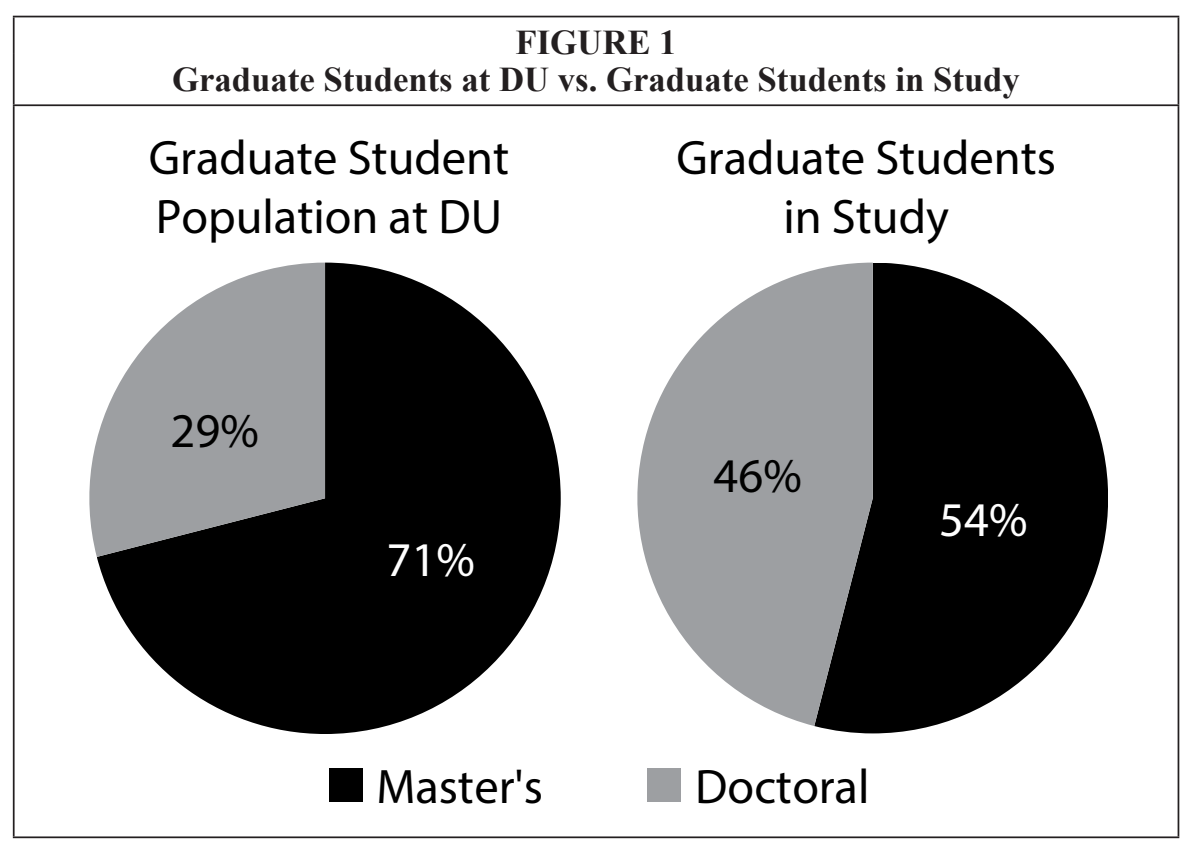


Further, our participant pool did not reflect the complete range of disciplines of students who attended the workshops, nor the larger graduate student makeup on campus (see table 1).

\begin{tabular}{|c|c|c|}
\hline \multicolumn{3}{|c|}{$\begin{array}{c}\text { TABLE } 1 \\
\text { Graduate Student Makeup Compared to Graduate Student Participation }\end{array}$} \\
\hline Academic Unit & $\begin{array}{c}\text { Percent of Graduate } \\
\text { Students Enrolled in Unit, } \\
\text { Fall } 2013\end{array}$ & $\begin{array}{c}\text { Percent of Focus } \\
\text { Group Participants } \\
\text { per Unit }\end{array}$ \\
\hline $\begin{array}{l}\text { Arts \& Humanities, Social Sciences } \\
\text { (including Professional Psychology) }\end{array}$ & 6 & 50 \\
\hline Education & 16 & 23 \\
\hline International Studies & 8 & 11.5 \\
\hline Social Work & 11 & 7.5 \\
\hline Theology & 0.3 & 4 \\
\hline Engineering and Computer Science & 2 & 4 \\
\hline Business & 16 & 0 \\
\hline Tax & 3 & 0 \\
\hline Natural Science \& Mathematics & 2 & 0 \\
\hline Law & 13 & 0 \\
\hline Graduate Studies & 1 & 0 \\
\hline University College & 18 & 0 \\
\hline \multicolumn{3}{|c|}{$\begin{array}{l}\text { Source: University of Denver Office of Institutional Research and Analysis, Admissions by Academic } \\
\text { Unit: New Graduate Students. Available online at: http://www.du.edu/ir/pdf/grad_admission_by_unit. } \\
\text { pdf [accessed } 14 \text { August 2015]. }\end{array}$} \\
\hline
\end{tabular}

Each focus group lasted 45 to 60 minutes, and the moderator presented participants with a series of open-ended, semistructured questions. The questions were centered on why the participants attended the workshop and were meant to solicit feedback on the workshop itself. In addition, the moderator sought feedback on Pivot as well as recommendations for promoting the workshop and other library services. The moderator also asked about the types of funding the participants were seeking in hopes of obtaining feedback on research and funding support for graduate students in general. Finally, the moderator prompted participants for ideas about the role of the library in graduate student support.

The moderator was intentional about listening carefully to responses, observing how participants answered, verbally summarizing responses, and seeking clarification when necessary. ${ }^{26}$ Each focus group was recorded, and an assistant took electronic notes during each session. After each focus group, the moderator and assistant debriefed and discussed major themes, and notes from these discussions were crafted into analytical memos, which were then used to inform questions posed during subsequent focus groups. Following each focus group, we created a transcription based on careful reviews of the recordings. To ensure validity and trustworthiness of the transcriptions, they were sent to participants as "member checks," ${ }^{27}$ which offer participants the opportunity to confirm, clarify, or change their responses, ${ }^{28}$ though no participants chose to do so.

We called upon constructivist grounded theory to analyze our data, as this approach is less structured and more adaptable than objectivist grounded theory. ${ }^{29}$ Rather than 
demanding that we use "procedures that increase complexity at the expense of experience, ${ }^{\prime 30}$ such as the application of jargon-laden labels, processual diagrams, conceptual maps, and the like, we felt that an approach that would allow us the flexibility to explore our data "afresh, again and again as [we] develop[ed] new ideas" ${ }^{31}$ would best suit our research needs. Further, we selected this approach because it acknowledges that reality is constructed by the interaction and interpretation of both participants and "investigators," 32 an insight we find particularly applicable to work with focus groups.

After multiple careful readings of each transcript, we color-coded the contents and initially placed them into one or more of five categories (these categories emerged from the data, but, due to the nature of the responses we garnered during the focus groups, they also loosely reflected the types of questions we asked): workshop feedback; feedback on Pivot; reasons for attending the workshop; feedback on marketing and promotion of the workshop; general comments on graduate student research and funding support on campus; and other. We then created a codebook that emerged from the data for each category. The major and subcode labels were based on the diverse types of language participants used to describe similar phenomena and were applied lineby-line to participants' statements. Revisiting statements that were initially categorized as "other," we placed them into new or existing categories and applied appropriate coding labels. Within each category, we quantified codes (by focus group and across focus groups) to identify trends and outliers, and paid attention to disconfirming evidence and contradictory interpretations of the data. ${ }^{33}$

We then identified emergent themes across all categories and recorded what did not surface in the themes. It should be noted that this process involved continued engagement with the data and multiple rounds of categories before we decided on those we will report shortly. We also created an electronic data trail to ensure the accuracy of our findings. ${ }^{34}$ The results detailed in the next section describe the final categories and emergent themes from our analyses; the findings and recommendations discussed are based on our inquiry and are not meant to be generalizable, ${ }^{35}$ though we do suspect that the information presented will be transferable to those working in similar contexts. Specifically, we hope that what we learned from this study will be helpful to librarians working with students in small to mid-sized institutions that, due to decentralization or otherwise, do not have an established, well-funded, or robust campus unit that supports graduate-level grant- or funding-seeking activities.

\section{Focus Group Results}

Through analysis of the focus group transcripts, we grouped the final results into four broad categories: 1) feedback on the workshop; 2) graduate student needs; 3) opportunities for collaboration; and 4) outreach and promotion suggestions. In the process of transcribing and analyzing the data, the authors also noted related themes that emerged at various points in the conversations. The discussion below is organized by the four categories as well as the two themes that emerged: the importance of faculty and peers in the socialization process and graduate student behaviors.

\section{Feedback on the Workshop}

The main intent of the focus groups was to solicit feedback on the library's grants research workshop; therefore, the majority of the comments focused on that area. Overall feedback on the grants workshop was generally positive, and most students reported that they were glad they attended. Interest in opportunities for funding fell largely between those who anticipated the need for this information for the future and those who required more immediate funding; for the latter, the time allotted for searching and the individualized help was valued more than for those who wanted more of an 
overview. Whatever their reasons for attending, most students were appreciative to be made aware of the resources available to them, found the workshop very helpful, and felt that it was time well spent. In response to what they found the most valuable about the workshop, many students were simply excited to learn that there was support for finding funding.

Focus Group 3, Participant 7: “I just never thought that as [a] graduate student, you can also look for funding yourself.... I never thought until I heard about the workshop, and I thought oh wow, I can actually do this!"

Focus Group 4, Participant 2: "I will admit to being absolutely shocked and elated that [the library] was offering workshops like that. What a great slate."

Comments about the effectiveness and ease of use of Pivot were also common. Workshop participants strongly encouraged the library to keep subscribing to Pivot or something similar and to further promote the availability of such a resource. Several focus group participants also noted that the hands-on element of the workshop was particularly helpful. Keyword development, however, seemed to be both useful and frustrating to some students.

Focus Group 2, Participant 2: "And I was a little overwhelmed with the search terms. I guess I could probably use some more guidance there. Seemed like I was getting nothing or 500, depending on what I entered."

Focus Group 4, Participant 3: “One of the most helpful parts was that we were all able to refine what keywords we were searching through Pivot, which helped me look more specifically at what I wanted."

There was also some misunderstanding of the purpose of the workshop. Although the majority knew the workshop was about finding grants, a few thought that we would be discussing the larger context of grants research rather than the specifics of searching, while a couple of others thought the workshop was about writing grants.

Suggestions for improving the workshop included providing printed handouts, extending the length of the workshop, and also creating separate workshops for masters and doctoral students. Many students felt that doctoral students had different needs and therefore would benefit from a more advanced workshop.

Focus Group 3, Participant 3: “To be honest, a difficulty for me is knowing how my research funding as a $\mathrm{PhD}$ student is different from what it was in my Master's program....in my Master's program, I was thinking in terms of conferences alone really. That was my only concern... so I had a purpose for writing this or that paper. Whereas as a PhD, I think it's different, but I'm not entirely sure what I should be looking for."

Participants also had ideas about additions to the workshop. We had already identified grant writing as a gap on campus, and this was mentioned numerous times by focus group participants; however, we hadn't realized that students were also seeking help understanding the bigger picture of grants research. The vast majority of students wanted the library to provide examples of successful grant proposals and also to hold panels on grant-writing tips with those who had acquired funding. 
Focus Group 2, Participant 3: “What does a good grant proposal look like? ...even a one-page quick guide [with] some successful grants that have been proposed by DU grad students or undergrad students that have been successful in securing grants...as some sort of reference."

Focus Group 4, Participant 2: “It brings up this idea to me about incentivizing success stories, so if you could say Fred Flintstone in psychology or mathematics. He really got it, and this is what he did, that would be like oh. Oh! It really pays off. That might be helpful for your presenters."

\section{Graduate Student Needs}

While the majority of the focus group questions centered on the library's grants workshops, we also asked participants how the library could better support their overall research. Surprisingly, the majority of the comments did not actually focus on library services; participants openly expressed their concerns about the lack of support, particularly monetary support, for graduate students on campus. Of particular frustration was the lack of a centralized location or space for identifying campus funding opportunities, confusion about the procedures for applying for internal funding, and the limited availability of money.

Graduate students also expressed concern about the lack of a detailed process for grant applications on campus and their needs for mentoring. For example, they hoped to receive feedback on why their internal grants were not successful, and they also wished that their faculty advisors were more aware of available resources.

\section{Opportunities for Collaboration}

Because graduate students expressed their frustrations with us about campuswide support, we asked how the library might assist with these issues. The majority of participants felt that the library could use its influence to develop a centralized resource for campus funding opportunities; in fact, several students suggested that our research guide on finding funding could be broadened to include campus opportunities such as scholarships and travel grants. They also asked for our assistance in hosting panels and presentations on successfully applying for grants and for help with the IRB process.

While students recognized that some of the services and resources suggested were beyond a traditional library's purview, they also identified the library as a central location or service point on campus. Students alluded to the cross-disciplinary nature of the library and considered it an ideal site for collaborative academic support services.

\section{Promotion and Marketing to Graduate Students}

In the focus group discussions about improvements to the workshop, a significant trend emerged concerning the need for the library to develop better communication strategies with graduate students. While the initial conversations were about the grants workshop, it soon became clear that the participants felt that graduate students were largely unaware of many of the library's services and resources. In response, we asked for their suggestions on promoting library workshops and services. While many participants regularly checked their e-mail as well as social networking sites, they most often noted that either a peer or faculty advisor recommending a workshop or service was the most effective advertising method.

Focus Group 2, Participant 1: "If you could disseminate information to faculty, that would be useful so they can bring it up in class, and more people will be reached." 
Focus Group 5, Participant 1: “The way I learned about this [workshop] was through the Graduate Student Government e-mail....in terms of recommendations, ... [if the] liaison in the department conveys information, that sounds like a great way to do it...Because I think it makes sense that each department or school has its own method of communicating, and students are used to that, and therefore that's where they're expecting to get info."

At our institution, the lack of a centralized or reliable method of communication for all graduate students offers a challenge to librarians organizing a suite of workshops to supplement their education. We discovered, too, that one of our main sources of communicating about library services - the liaison communication channel - was not always effective if the person responsible for passing along e-mails about services failed to do so.

\section{Emergent Themes and Discussion Importance of Faculty and Peers}

One unexpected theme that emerged from our discussions with participants is that the graduate students really enjoyed talking to each other and wanted more opportunities to meet other students outside their departments, as well as to learn about other faculty research on campus. This short conversation illustrates this general theme from the focus groups:

Focus Group 2, Participant 1: “One thing that I kept thinking about is that I want to learn about what other faculty in other schools and colleges are working on, are there any projects that they need help with that I may be perhaps interested in."

Focus Group 2, Participant 2: “Interdepartmental communication. I think my department does a great job, but I don't hear much about what other graduate students are doing on campus... more interdepartmental communication about... cross-disciplinary stuff."

Focus Group 2, Participant 3: "I would be curious what happens in the school of social work, very similar-minded areas - [for example], if they're having different speakers [that would be of interest to other disciplines]."

And the following statement was echoed in various ways throughout the sessions:

Focus Group 3, Participant 5: "It was nice having this focus group."

These findings prompted us to extend our thinking about the integration of the student into the culture of the local department and larger discipline of study as a means of preventing attrition, and the socialization of graduate students into the academic conversations within their disciplines. One concern with graduate education is its high rate of attrition, which, according to several studies, hovers somewhere between 40 and 50 percent. ${ }^{36}$ Surprisingly, lack of academic ability is not the cause of most students leaving doctoral programs prior to completion; studies have shown that there is little difference in qualifications between those who complete the doctorate and those who do not. ${ }^{37}$ Most researchers who study doctoral attrition attribute this problem to a combination of factors, not the least of which is the student's integration into the culture of the local department and larger discipline of study. ${ }^{38}$ To describe this process of integration, Austin ${ }^{39}$ calls upon research in organizational socialization, describing the graduate study period 
as a time when students learn about the culture of the group, including its values, attitudes, and expectations. ${ }^{40}$

During the past several decades, scholars in a range of disciplines have built a robust literature on graduate student socialization. Models of socialization suggest that new graduate students depend upon those within the university for clues on how to behave.$^{41}$ Doctoral students look to faculty and peers for more than simply acquiring the skills to succeed in a discipline. Through these interactions, they begin to master the norms and values that drive the discipline. Faculty members play a critical role in this socialization process. ${ }^{42}$ Students learn about faculty roles and responsibilities through observing faculty in action and listening to conversations. ${ }^{43}$ Students also use both informal and formal conversations with their advisors to construct their image of faculty life. ${ }^{44}$ While our focus groups are not representative of the larger graduate student population on campus, it was clear that graduate students thought of librarians as mediators; they wanted us to help them understand academic culture and to build bridges with their faculty.

According to the literature, doctoral students also look to advanced students in their programs for information about how to succeed, which may explain why the students in our study were so interested in meeting and talking with each other. Although Leonard L. Baird argued that faculty are the primary agents of socialization, ${ }^{45}$ many scholars have found that students interact with their peers more than their faculty. ${ }^{46}$ In a survey of 50 doctoral students in two departments, John C. Weidman and Elizabeth L. Stein found that 83.6 percent of students sometimes engaged in social conversation with faculty, but 90.9 percent engaged in social conversation with their peers. ${ }^{47}$ Students look to their peers for more than just social chatter. Eighty-five percent of students often discussed topics in the field or other topics of intellectual interest with their peers compared with 69.1 percent who discussed similar topics with faculty. ${ }^{48}$ Similarly, in a survey of doctoral students in four disciplines, Melissa S. Anderson and Judith P. Swazey found that students reported learning more about academic norms from their peers than from their professors. ${ }^{49}$

Students in our focus groups described themselves as being in silos when referring to their departments. Does the interdisciplinary nature of current academic research provide new openings for librarians to collaborate with departments and graduate student organizations to facilitate conversations across disciplines? In the future, we hope to develop partnerships with others on campus who are interested in hosting events that would facilitate such discussions.

\section{Graduate Student Behaviors}

Earlier we reported recommendations from our focus groups concerning marketing and outreach, but these are sometimes at odds with the reality of graduate students' lives. Faculty and peers are important sources of information, but graduate students have commitments, habits, and behaviors that limit librarians' abilities to connect effectively with students about workshops and other services. Graduate students are overcommitted, with little time to seek out nonessential information and opportunities. For example, this exchange between participants in this group reveals such challenges:

Focus Group 4, Participant 6: "As graduate students, we're pretty busy, most of [us] work and do school and volunteer, etcetera. If the workshops are more than an hour, that is a challenge."

Focus Group 4, Participant 4 and 6: "Not attending anything that is two hours." 
Focus Group 4, Participant 2: "I [have] all Saturday classes, and many of my colleagues are working, so for them even to come over [to the library] sometimes is a little bit difficult, even though we do come over here."

Focus group participants identified various barriers to learning about and attending library workshops:

- Tuning out extraneous information (such as deleting e-mails identified as general because graduate students tend to be specialized; reading departmental and sometimes graduate student newsletters, but not general newsletters)

- Not visiting the centralized campus website except for specific reasons

- "Holing up"

- Having limited time on campus (staying in departmental buildings; seldom visiting the library)

- Not unexpectedly, asking their professor, advisor, or program coordinator for direction, thus relying solely upon these mentors for information about workshops and events

The graduate students in one focus group were mixed on whether their peers would attend campuswide orientations. In terms of direct communication, some students have mailboxes while others do not. Comments providing insights into the behaviors of and challenges for graduate students include these observations from one group:

Focus Group 3, Participant 5: "I think graduate students have the best of intentions, but at least in our department, I know many people who have never left [the departmental buildings] and know those two buildings and the gym, and that's about it."

Focus Group 3, Participant 1: "I am so much more likely to read an e-mail from my department chair than from [the division]."

One student did state that graduate students ought to take initiative to be successful in finding funding opportunities:

Focus Group 3, Participant 5: "I think a large part of successfully getting funding for graduate students is just having initiative. And I'll be blunt,...but a fair amount of the burden should fall on us. Does fall on us and should fall on us."

Participants were made aware of the grants workshop in a variety of ways, with the departmental distribution list being most common; others found out via the graduate student newsletter, graduate student orientation, library website, friends or peers, campus and library e-mails-and one person by chance because he or she was in the Research Center area.

Although no preferred avenue of communication emerged from the focus groups, we have found better success promoting the workshops via departmental e-mail or graduate-specific newsletters and then branching out into other recommended avenues. Consistent with the research literature, the students identified faculty as crucial sources of information and as mentors, so the fact that faculty are perceived to be out of the loop about essential resources is troubling to students.

\section{Workshop Improvements}

Based upon participants' suggested improvements, we revised the workshop and provided additional information on the LibGuide. We more explicitly stated in the 
promotional description that we would be demonstrating and searching Pivot, and we provided a link to the LibGuide for those unable to attend the workshop. Using the registration form, we asked students what types of funding they were seeking so that we could begin tailoring the workshop beforehand, although we still engaged with the topics offered by those who dropped in. We added a PowerPoint presentation to the home tab in the LibGuide that details the process of accessing the LibGuide, registering for Pivot, and developing search strategies. We now also provide printouts at the workshop for note taking and later referral, which we hope will remind students to contact us for consultations.

In light of conversations in the focus group, we have also made concerted efforts to try out new methods of advertising the workshops to graduate students. In addition to posting the workshop schedule to our website, Facebook, and Twitter, we also send out e-mail announcements to each departmental listserv (via the administrative assistant for each department) as well as include information in the biweekly graduate student newsletter. Communication continues to be a problem due to the decentralized nature of graduate student services, and we are monitoring the most successful avenues for workshop promotion.

Since Pivot was considered very valuable, we altered the workshop so that more time was spent on individuals exploring the database and testing various search strategies. As this latter move didn't take into account those who signed up for the workshop who were simply seeking awareness, we then returned to the original format, which, although not perfect, was more balanced. Essentially, the structure of the workshop itself allows for more inclusiveness because it is flexible and can be adjusted to the audience. For example, one focus group attendee mentioned that she is part of a center within the graduate program of international studies and subsequently invited us to give the workshop to all the students in that center so that they could collectively start looking for funding; the basic structure of the workshop was easily adapted to this more specialized audience.

As a result of the knowledge gathered from our focus groups, we have also been working to create deeper connections to graduate student groups on campus. The humanities and social sciences division invited us to give the workshop to their students, and the president of the graduate student government asked us to be part of a panel that included a representative from the graduate studies office, who covered information about the process of applying for internal grants, and a faculty member who talked about her strategies for successfully applying for grants when she was a graduate student. By starting to build connections with other departments and individuals on campus, we plan to collaborate to expand out from the workshop.

Many ideas generated in the focus groups for improving the workshop to provide needed additional support for graduate students can be implemented through future campus collaborations: working with the graduate studies office to identify all DU funding opportunities open to graduate students and creating a central place to find them on the university website; teaming up with the graduate student government to bring together individuals who can talk about the larger world of grants, what successful and unsuccessful applications look like, and how to meet the requirements for applying; and partnering with the writing program and the IRB office to hold workshops on grant writing and the IRB process.

\section{Study Limitations}

Reflecting on our findings, we conclude that our methodology and analysis allowed us to answer the majority of our questions regarding the workshop, graduate student needs, and the library's role in providing support in meeting these needs. Below, we 
will reflect on not only the strengths of our study, but also its limitations. First, offering graduate students a $\$ 25$ Amazon gift card proved to be a smart incentive, as we recognized that most students could find a way to make use of this item. We also found that discussing and presenting a signup sheet for the focus groups at the conclusion of the workshops was an excellent way to attract participants. We reasoned that, since funding was on their mind, and a librarian was able to discuss the importance of the project face-to-face, students were compelled to participate. By requesting their contact information, we were easily able to follow up and provide them with more information about the study. Certainly, not all participants who signed up actually came, but this is bound to happen when working with busy graduate students.

Since all three authors had additional responsibilities at the time of the study, individually interviewing workshop attendees would not have been logistically possible. Thus, the focus group model was a feasible alternative that also allowed participants to "react to and build on the responses of other group members," ${ }^{50}$ and we found that "differences of opinion among group members also help[ed] researchers identify how and why individuals embrace or reject particular ideas, communications, or products." 51 The latter was particularly useful in that it helped us to highlight differences in disciplinary needs as well as differences between the needs of masters-level and doctoral students.

Because grant seeking tends to occur before or during a specific time of need rather than in a systematic or ongoing way, we chose not to conduct repeated focus groups with the same participants over the course of the academic year. If we had done so in an effort to determine if they had been able to successfully apply for and receive funding, many participants would have likely stated that they had not yet encountered a need to seek funding. While we did ask whether anyone had, following the workshop, applied for or received funding (indeed, many reported that they had not yet had the need to do so), we focused on the workshop itself and hoped to identify ways to improve it to better serve students. This approach seemed to make the best use of our time, though suggestions for how we might follow up with individuals are discussed in the section to follow.

The subjective nature of soliciting, documenting, and interpreting qualitative data was viewed as a potential asset, as two of the authors were enrolled in graduate programs at the time of the study (one, in a masters-level program; the other, in a doctoral program). Thus, they had similar experiences with seeking funding at the campus level, offering what Katrina M. Daytner describes as "unique insights into the understanding of the phenomenon." 52 In using a constructivist grounded theory approach to data analysis, we understood that our "discovered reality arises from the interactive process and its temporal, cultural, and structural contexts. Researcher and subjects frame that interaction and confer meaning on it." ${ }^{53}$ We did attempt to monitor the role of bias in our study, however, and having three authors allowed us to do so fairly easily, as the use of multiple investigators acted as something of a safeguard.

Due to the limited nature of our study questions, we did not triangulate our data. For example, while the participants included more than half of all workshop attendees for 2013-2014, our data sources were limited to only the focus groups. Incorporating a second or third data source, such as survey responses, observations of search behavior, or interviews with faculty, would have strengthened our study. Finally, another obvious but important limitation of this study is that our results are in no way generalizable (which was never our aim), and we sought only to shed light on our local context and graduate student population. However, as previously mentioned, we hope that our results might be helpful and even provide a roadmap for those librarians working in similar contexts. 


\section{Areas for Future Research}

Going forward, those conducting similar studies might give increased attention to the demographic makeup of participants. Rather than simply grouping participants by discipline and as either masters-level or doctoral-level, we might take gender identity, sexual orientation, race, nationality, and other factors into account. By doing so, we might be able to identify experiences and trends specific to, for example, women or minorities. This would then allow us to attempt to better meet the needs of these user groups.

As David W. Stewart, Prem N. Shamdasani, and Dennis W. Rook note, focus groups are often used early in research and are followed by quantitative studies that use larger sample sizes. ${ }^{54}$ We suggest that a follow-up study seeking feedback from workshop attendees would allow us to quantify not only how many workshop participants have been successful in securing funding but how long after attending the workshop it took them to do so. Given the variations in funding cycles and time of need, we feel that this approach would best allow us to determine the long-term success of one important goal of the workshop.

\section{Conclusion}

Graduate students are often inadequately prepared for the rigors of graduate-level research and study. ${ }^{55}$ In addition to requiring assistance with literature review searching and citation management, they frequently struggle with writing, researching, and applying for grant opportunities and external funding. Through our case study, we have shown that librarians can be effective in helping to fill these gaps in the graduate student experience. Given today's tight job market for academic positions, as well as the large sums spent in support of graduate programs, it is imperative for librarians not only to develop programming in this area but also to prove instructional effectiveness. ${ }^{56}$ Finally, the additional themes that emerged in our focus groups related to graduate student socialization and research behaviors suggests that librarians have an important role to play in preparing graduate students to be successful in the evolving nature of the academy.

\section{Notes}

1. Allan Gibb, Gay Haskins, and Ian Robertson, "Leading the Entrepreneurial University: Meeting the Entrepreneurial Development Needs of Higher Education Institutions," in Universities in Change: Managing Higher Education Institutions in the Age of Globalization, eds. Andreas Altmann and Bernd Ebersberger (New York: Springer, 2013), 9-45.

2. Magnus Gulbrandsen and Jens-Christian Smeby, "Industry Funding and University Professors' Research Performance," Research Policy 34, no. 6 (2005): 932-50.

3. Ann E. Austin, "Preparing the Next Generation of Faculty: Graduate School as Socialization to the Academic Career," Journal of Higher Education 73, no. 1 (2002): 94-122.

4. Ibid.

5. University of Denver Office of Institutional Research and Analysis, Common Data Set 2013-2014, available online at http://www.du.edu/ir/media/documents/cds_2013.pdf [accessed 15 July 2014].

6. Bonnie Holday, Kenneth A. Weaver, and Linda B. Nilson, "Revisioning Graduate Professional-Development Programs," College Teaching 55, no. 3 (2007): 99-103.

7. Jason L. Pontius and Shaun R. Harper, "Principles for Good Practice in Graduate and Professional Student Engagement," New Directions for Student Services 2006, no. 115 (2006): 47-58.

8. See Sara Delamont, Paul Atkinson, and Odette Parry, The Doctoral Experience: Success and Failure in Graduate School (London: Falmer Press, 2000); and Barbara E. Lovitts, "The Transition to Independent Research: Who Makes It, Who Doesn't, and Why," Journal of Higher Education 79, no. 3 (2008): 296-325.

9. Austin, "Preparing the Next Generation of Faculty." 
10. Barbara Blummer, "Providing Library Instruction to Graduate Students: A Review of the Literature," Public Services Quarterly 5, no. 1 (2009): 15-39.

11. Barbara A. Shaffer, "Graduate Student Library Research Skills: Is Online Instruction Effective?" Journal of Library \& Information Services in Distance Learning 5, no. 1/2 (2011): 35-55.

12. Hannah Gascho Rempel, "A Longitudinal Assessment of Graduate Student Research Behavior," College and Research Libraries 71, no. 6 (2010): 532-47.

13. Colleen S. Harris, "The Case for Partnering Doctoral Students with Librarians: A Synthesis of the Literatures," Library Review 60, no. 7 (2011): 599-620.

14. Stacy N. Brinkman and Arianne A. Hartsell-Gundy, "Building Trust to Relieve Graduate Student Research Anxiety," Public Services Quarterly 8, no. 1 (2012): 26-39.

15. Michelle Holschuh Simmons, "Librarians as Disciplinary Discourse Mediators: Using Genre Theory to Move toward Critical Information Literacy," portal: Libraries and the Academy 5, no. 3 (2005): 297-311.

16. Christie Peters and Anita Riley Dryden, "Assessing the Academic Library's Role in CampusWide Research Data Management: A First Step at the University of Houston," Science \& Technology Libraries 30, no. 4 (2011): 387-403.

17. Ibid.

18. Chris M. Golde, "The Role of the Department and Discipline in Doctoral Student Attrition: Lessons from Four Departments," Journal of Higher Education 76, no. 6 (2005): 669-700.

19. Ibid.

20. University of Denver, "Student Profiles," 2014, available online at www.du.edu/explore/ studentprofiles.html [accessed 15 July 2014].

21. For information on the appropriate usage and rigor of focus group methodology, please see David W. Stewart, Prem N. Shamdasani, and Dennis W. Rook, "Focus Groups in Practice," in Focus Groups, 2nd ed. (Thousand Oaks, Calif.: SAGE Publications, Ltd., 2007), 135-53.

22. Robert K. Merton, "The Focussed Interview and Focus Groups: Continuities and Discontinuities," Public Opinion Quarterly 51, no. 4 (1987): 550-66.

23. Bobby J. Calder, "Focus Groups and the Nature of Qualitative Marketing Research," Journal of Marketing Research 14, no. 3 (1977): 353-64.

24. Ibid.

25. Katrina M. Daytner, Validity in Qualitative Research: Application of Safeguards (Report No. ED516416), paper presented at the 18th annual meeting of the Ethnographic and Qualitative Research in Education conference, Cedarville, Ohio, June 10, 2006.

26. Richard A. Krueger, "Questions Focus Group Analysts Must Face," in Analyzing and Reporting Focus Group Results: Focus Group Kit 6 (Thousand Oaks, Calif.: SAGE Publications, 1998), 61-78.

27. Daytner, Validity in Qualitative Research.

28. Krueger, "Questions Focus Group Analysts Must Face."

29. John W. Creswell, "Five Qualitative Approaches to Inquiry," in Qualitative Inquiry and Research Design: Choosing Among Five Approaches (Los Angeles: Sage, 2013), 69-110.

30. Kathy Charmaz, "Grounded Theory: Objectivist and Constructivist Methods," in Handbook of Qualitative Research, eds. Norman K. Denzin and Yvonna S. Lincoln (Thousand Oaks, Calif.: Sage, 2000), 525.

31. Ibid, 526 .

32. Ibid.

33. Daytner, Validity in Qualitative Research.

34. Ibid.

35. Krueger, "Questions Focus Group Analysts Must Face."

36. For a discussion of graduate student attrition and socialization, see Chris M. Golde, "The Role of the Department and Discipline in Doctoral Student Attrition: Lessons from Four Departments," Journal of Higher Education 76, no. 6 (2005): 669-700; Susan K. Gardner, "Student and Faculty Attributions of Attrition in High and Low-completing Doctoral Programs in the United States," Higher Education 58, no. 1 (2009): 97-112; Steve Bain, LaVonne Fedynich, and Melody Knight, "The Successful Graduate Student: A Review of the Factors for Success," Journal of Academic and Business Ethics 3 (2011): 1-9; Susan K. Gardner, "Fitting the Mold of Graduate School: A Qualitative Study of Socialization in Doctoral Education," Innovative Higher Education 33, no. 2 (2008): 125-38.

37. Gardner, "Fitting the Mold of Graduate School."

38. Ibid.

39. Austin, "Preparing the Next Generation of Faculty."

40. Mary Corcoran and Shirley M. Clark, "Professional Socialization and Contemporary Career Attitudes of Three Faculty Generations," Research in Higher Education 20, no. 2 (1984): 131-53.

41. John C. Weidman and Elizabeth L. Stein, "Socialization of Doctoral Students to Academic 
Norms," Research in Higher Education 44, no. 6 (2003): 641-56.

42. Weidman and Stein, "Socialization of Doctoral Students to Academic Norms."

43. Jeffery P. Beiber and Linda K. Worley, "Conceptualizing the Academic Life: Graduate Students' Perspectives," Journal of Higher Education 77, no. 6 (2006): 1009-35.

44. Austin, "Preparing the Next Generation of Faculty."

45. Leonard L. Baird, The Stages of the Doctoral Career: Socialization and its Consequences, Report No. ED348925 (Washington, D.C.: Educational Resources Information Center, 1992).

46. For a discussion of graduate students and the effects of interactions with peers, see Weidman and Stein, "Socialization of Doctoral Students to Academic Norms," and Melissa S. Anderson and Judith P. Swazey, "Reflections on the Graduate Student Experience: An Overview," New Directions for Higher Education 1998, no. 101 (1998): 3-13.

47. Weidman and Stein, "Socialization of Doctoral Students to Academic Norms."

48. Ibid.

49. Anderson and Swazey, "Reflections on the Graduate Student Experience."

50. David W. Stewart, Prem N. Shamdasani, and Dennis W. Rook, Focus Groups: Theory and Practice, 2nd ed. (Thousand Oaks, Calif.: SAGE Publications, 2007), 43.

51. Ibid.

52. Daytner, Validity in Qualitative Research, 5.

53. Charmaz, "Grounded Theory," 524.

54. Stewart, Shamdasani, and Rook, Focus Groups.

55. Harris, "The Case for Partnering Doctoral Students with Librarians."

56. Austin, "Preparing the Next Generation of Faculty." 